\title{
Pesquisa com crianças: entre a experiência no campo e a escrita do texto
}

\author{
Research with children: \\ between the experience in the field and the writing of the text
}

\author{
Irene Carrillo Romero BEBER ${ }^{1}$ \\ Maria Carmen Silveira BARBOSA ${ }^{2}$
}

\begin{abstract}
Resumo
A tessitura do texto foca em dois momentos do desenvolvimento da pesquisa com crianças. O primeiro é relativo ao processo de observação: estar com as crianças numa atitude de escuta, marcada pela presença física do pesquisador na captura das cenas e episódios e nos processos de interação entre o pesquisador e os sujeitos da pesquisa. $\mathrm{O}$ segundo diz respeito ao processo de distanciamento da escrita, a teorização das açóes vivenciadas no campo de pesquisa. Os dados gerados indicam que pesquisar com crianças envolve interaçóes afetivas e corpóreas, ou seja, a presença pessoal afeta e é afetada pelas experiências vividas no campo.
\end{abstract}

Palavras-chave: Pesquisa. Escrita. Educação Infantil. Corporeidade.
Abstract

The writing of the text focuses on two moments in the development of research with children. The first moment is related to the process of observation: being with the children in an attitude of listening, which is marked by the physical presence of the researcher in the capture of scenes and episodes, and in the processes of interaction between the researcher and the subjects. The second moment has to do with the process of distancing during the writing, the theorizing of actions experienced in the field of research. The data generated indicate that research with children involves affective and body interactions, i. e. the personal presence affects and is affected by the experiences lived in the field.

Keywords: Research, Writing, Children Education, Corporeity

1 Doutora em Educação da UFRGS. Professora Adjunta IV no Curso de Pedagogia, Campus de Sinop na Universidade do Estado de Mato Grosso. Atua na área de Educação, participando em projetos de pesquisa e extensão. Atualmente as interações entre adultos e crianças nos espaços da escola de Educação Infantil, com enfoque na corporeidade e nas experiências de aprendizagem com o corpo em movimento das crianças. Universidade do Estado de Mato Grosso, Campus de Sinop. Av. dos Ingás no 3001, Centro, 78550000 - Sinop, MT - Brasil. Telefone: (066) 35112100. E-mail: <irenecrbeber@gmail.com>.

2 Doutorado em Educação pela Universidade Estadual de Campinas, Brasil (2000). Professor Titular da Universidade Federal do Rio Grande do Sul, Brasil. Faculdade de Educaçấo, Departamento de Estudos Especializados. Avenida Paulo da Gama, s/no Farroupilha 90046-900 - Porto Alegre, RS - Brasil Telefone: (51) 33163099. E-mail: <licabarbosa@ufrgs.br>.

R. Educ. Públ. v. 28 n. 67

p. $63-83$ jan./abr. 2019 


\section{Abrindo a conversa}

O desafio teórico-metodológico de pesquisar com as crianças tem instigado um número cada vez maior de pesquisadores, que buscam compreender seus mundos e suas experiências. Esse processo nos coloca diante da necessidade de ampliar os nossos entendimentos acerca dos seus modos de agir, comunicar, aprender e interagir. Adentrar nesse universo é sem dúvida um dos grandes desafios aos pesquisadores que buscam pesquisar com as crianças, incluindo-as na geração de dados como protagonistas, como agentes sociais ativos de suas primeiras impressóes do mundo.

Nos últimos 20 anos, presenciamos o crescimento substancial de grupos de pesquisa, em especial os ligados aos Programas de Pós-Graduação ${ }^{3}$, que se propóem a pesquisar o universo infantil a partir de metodologias que ampliam a participação efetiva das crianças na produção e compreensão das experiências vividas. Esse volume de estudos tem potencializado igualmente o número de livros e artigos que tematizam a experiência de pesquisa com crianças; entre eles, se encontram Faria et al. (1999), Lopes da Silva, Nunes e Macedo (2002), Cohan (2005), Cruz (2008), Filho e Prado (2011) e Guimarães (2011).

Assim, este texto busca compartilhar, a partir da nossa experiência de pesquisa, os desafios de se operar com os instrumentais metodológicos da etnografia, evidenciando como a utilização desses instrumentos de pesquisa nos permitiu interagir com as crianças. Ao assumirmos uma atitude de escuta e acuidade perceptiva, pudemos compreender como a presença do pesquisador interfere, amplia vínculos, modifica o ambiente no qual a criança está inserida e como esses aspectos devem ser operacionalizados no desenvolvimento da pesquisa.

$\mathrm{Na}$ perspectiva etnográfica, o pesquisador é primeiramente percebido como um estranho ${ }^{4}$ que se insere no campo. No decorrer da investigaçáo, constrói estratégias de aproximação com o intuito de capturar as manifestações das crianças e durante o desenvolvimento da pesquisa acaba sendo capturado, envolvido nessa relação, como nos ensina Geertz (2008, p. 20): "fazer etnografia é estabelecer relaçóes". Nessa perspectiva, a ação de pesquisar com as crianças implica numa

3 No IV Seminário do Grupeci, em 2014, reuniram-se cerca de 70 grupos, com a apresentaçáo de 200 trabalhos, divididos em cinco eixos temáticos diferentes.

4 O termo estranho aqui faz referência ao sentido de alguém que nâo pertence ao grupo. Os estudos antropológicos fazem menção a esse contexto: o estranho (ou ainda o estrangeiro) como alguém que não é do grupo, e que precisa conquistar seu espaço e estabelecer relaçóes. 
atitude de escuta do pesquisador, indispensável nos movimentos apreensão das experiências de como as crianças percebem o mundo 5 .

Ao revisarmos a produçáo nessa área, pudemos identificar que os trabalhos que abordam ${ }^{6}$ metodologicamente as dinâmicas de pesquisa com crianças com frequência abordam as complexas interaçôes dos pesquisadores com as crianças, mencionam os aspectos relativos às suas açóes, às intencionalidades e iniciativas de conhecer, bem como as trocas interativas com os demais sujeitos envolvidos.

Esses estudos refletem sobre as multiplicidades de faces presentes nas dinâmicas que envolvem a ação de pesquisar com as crianças. Como apreender os sentidos das suas experiências nas brincadeiras? Como capturar e avaliar os seus processos de aprendizagens? Como analisar e traduzir pela escrita o observado? Como narrar as cenas e os episódios, e como manter uma postura ética na pesquisa, interagir com elas sem invadir de modo excessivo seu espaço?

Neste texto, não abordaremos todos esses aspectos. No entanto, pretendemos nos deter na análise compreensiva de dois momentos igualmente significativos que permeiam o processo de pesquisa. $\mathrm{O}$ primeiro aspecto está relacionado à inserção no campo de pesquisa, à experiência de conviver com as crianças numa perspectiva de escuta, numa relação que envolve a presença física do pesquisador. É o instante em que suas estratégias de pesquisa precisam possibilitar o capturar, apreender e compreender as açôes das crianças e dos demais envolvidos na pesquisa. Esses procedimentos exigem do pesquisador uma atitude ativa e intencional em dar visibilidade às açóes e iniciativas de conhecer e se comunicar das crianças.

$\mathrm{Na}$ experiência de pesquisa vivenciada, a nossa interação se efetivou, na maioria das situaçóes, pela via da corporeidade, ou seja, na intercomunicação corporal, pelo olhar, no toque, uma comunicação não centralizada na oralidade, uma vez que as crianças pequenas não conseguem se expressar plenamente pela fala. A expressão de seus desejos é manifestada em gestos, movimentos, atitudes que evidenciam suas intencionalidades. Nesses processos, a presença física do pesquisador é um fator preponderante que em algumas situaçóes aproxima, facilita

5 Em 1989, foi publicado no Brasil um clássico artigo de Clifford Geertz denominado "Estar lá, escrever aqui”, que versa sobre a produção da antropologia no momento da escrita. Esse texto tornou-se referência na antropologia contemporânea. Também Claude Lévi-Strauss (1977) havia trabalhado com os conceitos de Olhar, escutar, ler em um livro sobre antropologia e arte. No Brasil, o antropólogo Roberto Cardoso de Oliveira inspirou-se e proferiu uma palestra com tema semelhante na UNICAMP: "O Trabalho do Antropólogo: Olhar, Ouvir, Escrever”. Nós, seguindo nessa jornada, nos inspiramos nessa dualidade complementar para refletir sobre questốes metodológicas na pesquisa com crianças.

6 Muitas teses e dissertaçōes desenvolveram metodologias e tiveram a participação efetiva das crianças. Entre elas, podermos citar Beber (2014), Vargas (2014), Gobbato (2011), Coutinho (2010) e Buss (2012). 
as interações. Em outras ocasióes, as crianças rejeitam a presença observadora do pesquisador, uma vez que ela interfere no desenvolvimento da cena ou do episódio em curso. A aceitação pela criança dessa presença observadora precisa ser conquistada e negociada, ao longo do processo de inserção no campo de pesquisa.

O segundo aspecto da pesquisa destacado neste texto está relacionado ao processo de distanciamento, o momento de teorizaçáo e de escrita dos processos vividos no campo de pesquisa. Trata-se do exercício de escrita, no qual se busca significar num outro plano as experiências e aprendizagens vivenciadas. Entendemos que a interpretação densa e criteriosa dos dados não é possível sem o esforço do distanciamento; no entanto, o exercício da escrita envolve um complexo movimento entre o distanciamento e a aproximação. Ao mesmo tempo em precisamos nos distanciar, o campo não sai de nós - pois ele está em nós. $\mathrm{O}$ processo de análise/compreensão implica necessariamente no reconhecimento das aprendizagens vividas por nós e pelas crianças no campo, ou seja, compreender em que medida fomos impactados pela experiência de pesquisa com as crianças, $o$ que elas nos mostraram com seus corpos em movimento no contexto investigado.

\section{Organização metodológica do estudo}

A experiência de pesquisa ${ }^{7}$ foi desenvolvida numa instituição pública que atende crianças de 0 a 5 anos, num município da Região Norte do Mato Grosso. O grupo constituía-se de 25 crianças, com idades entre 2 e 3 anos. Além das crianças, foram objeto de observação e análise os adultos que se revezavam no atendimento de cuidado e educação das crianças. Ao todo foram seis adultos, sendo duas professoras e quatro auxiliares. A geração dos dados se efetivou a partir da observação direta com auxílio de filmagens, fotografias e anotaçôes no diário de campo.

Com o intuito de potencializar as dinâmicas de geração dos dados, afinamos o uso dos instrumentais teórico-metodológicos da perspectiva etnográfica de Geertz (1989), da escuta sensível desenvolvida por Barbier (2007) e da abordagem fenomenológica de Merleau-Ponty (1994, 2004, 2006). A partir da composição dessa tríade metodológica, foi delineado o que, ousamos dizer, pode ser compreendido como um instrumento metodológico: o olhar em $3 D$.

7 A experiência de pesquisa culminou com a tese de doutorado em Educação As experiências do corpo em movimento das crianças pequenas: Reflexôes para a pedagogia da infância, um estudo que buscou apreender as dinâmicas do corpo em movimento das crianças e as interaçóes entre adultos e crianças nos espaços da creche. 
O desafio da pesquisa era construir um olhar e uma observação densa em perspectiva, com os quais pudéssemos desenvolver um olhar ampliado de vários ângulos, uma vez que o objetivo central do estudo era evidenciar como as crianças de 2 a 3 anos manifestam sua corporeidade e, por meio das açóes autônomas e criativas, produzem suas aprendizagens, significam e recriam os objetos e os espaços. Como sinaliza Beber (2014), com o corpo em movimento, a crianças produzem narrativas que expressam suas intencionalidades e percepçóes sobre o mundo e as coisas.

Assim, ao desenvolvermos o olhar em 3D como um recurso metodológico, buscamos referência e analogia à metáfora da visão tridimensional em $3 \mathrm{D}$ utilizada pelo cinema. Nela, a formaçáo de uma imagem em três dimensóes, de fato, náo existe. $\mathrm{O}$ efeito é conseguido graças à maneira como o cérebro humano percebe as imagens. $\mathrm{Na}$ prática, para que haja uma imagem $3 \mathrm{D}$, são necessárias duas imagens sobrepostas, projetadas em ângulos diferentes. Em outras palavras, ao perceber que se tratam de duas imagens, ou imagens que não estão perfeitamente alinhadas entre si, o cérebro humano intuitivamente tenta alinhá-las e, para isso, coloca uma em primeiro plano e outra em segundo.

O resultado obtido nesse processo simula a sensação de profundidade, dando a nítida impressáo de que uma imagem está mais próxima do que a outra. Esse é um processo natural do olho humano, uma vez que vemos em três dimensóes. $\mathrm{O}$ cinema buscou desenvolver tecnologias que reproduzissem a visão humana, visto que o olho e o cérebro constituem uma dimensão tridimensional, em perspectiva.

Nessa perspectiva, o instrumental metodológico do olhar em 3D, isso é, a visão tridimensional como técnica de pesquisa, não existe como uma ação específica, mas como uma atitude diante do observado, um conjunto de medidas, uma sintonia imersiva que permite ao pesquisador ser envolvido e capturado pela emoção de observar e descobrir diferentes nuances e dimensóes do vivido; ao mesmo tempo em que se observa, descreve, se percebe incluso no processo que observa e interpreta. Assim, quanto mais rica for a observação, mais acentuados e contundentes forem os detalhes, mais profunda poderá ser a compreensão da cena observada. $\mathrm{O}$ envolvimento e a conexão com os sujeitos dão profundidade ao observado, descrito, capturado.

É importante considerar que, se um olhar bidimensional na pesquisa se caracterizaria por processos mais descritivos daquilo que ocorre com os sujeitos no espaço, onde há um eu e um ele, um sujeito e um espaço, com toda a dimensão binária da cultura, no olhar em $3 D$ o esforço metodológico seria de observar a dinâmica relacional das açóes corpóreas e dos movimentos afetivos, como mais um elemento a ser considerado e não negado, subsumido.

No desenvolvimento de pesquisas com as crianças bem pequenas, que ainda se comunicam pouco pela oralidade, o olhar em $3 D$ poderia dar ênfase, 
no processo de geração dos dados, à dimensão afetiva presente na comunicação corporal entre as crianças e o pesquisador. A dimensão corpórea, a corporeidade como um elemento efetivo nos processos interativos manifestos nos gestos, trocas de olhares, movimentaçóes, no diálogo e narrativas não centradas na palavra. Enredos marcados pela escuta sensível, uma conexão que exige uma entrega completa de corpo inteiro, sem reservas do pesquisador na relação com as crianças. A dimensão afetiva foi historicamente combatida pelas abordagens positivistas de pesquisa, uma vez que para Descartes (2003, p. 37) "os sentidos nossos sentidos às vezes nos enganam"; na perspectiva do olhar em $3 D$, pelo contrário, os sentidos foram um elemento que conectou, afinou a comunicação e ajudou no estabelecimento de vínculos. Como afirma Merleau-Ponty (1996), percebemos com todos os sentidos juntos, não vemos apenas com os olhos, ouvimos com os ouvidos, mas sim com o corpo inteiro.

Enquanto tenho um corpo e através dele ajo no mundo, para mim o espaço e o tempo náo são uma soma de pontos justapostos, nem tampouco uma infinidade de relaçôes das quais minha consciência operaria a síntese e em que ela implicaria meu corpo, não estou no espaço e no tempo, não penso o espaço e o tempo, eu sou no espaço e no tempo, meu corpo aplica-se a eles e os abarca. (MERLEAUPONTY, 1996, p. 195).

A abordagem fenomenológica de Merleau-Ponty, que tem na corporeidade um elemento fundante da percepção e da conexão com o mundo, foi neste estudo um elemento teórico presente na compreensão e interpretação densa.

Dessa forma, com o intuito de abordar os dois aspectos relevantes no processo de produção de pesquisa sinalizados no início do texto, estar lá e escrever aqui, desdobramos nossa discussão em cinco tópicos: (1) a inserção no campo de pesquisa e a quebra de resistências; (2) o exercício da atitude de escuta e reorganização dos objetivos da pesquisa; (3) a observação das rotinas e o encontro com o inesperado; (4) a saída do campo: a escrita como uma experiência de teorizar o vivido; e (5) a experiência de partilha sobre os que as crianças nos ensinaram.

\subsection{A inserção no campo de pesquisa: a quebra de resistências}

A inserção no campo de pesquisa nos confrontou com o desafio de ver e perceber as crianças, o que nos possibilitou exercitar as técnicas e os instrumentos de pesquisa propostos no projeto inicial. No entanto, ao operarmos com os recursos 
metodológicos da etnografia, primeiramente nos deparamos com o desafio de quebrar as resistências e deixar de ser um estranho ${ }^{8}$, um invasor, alguém que altera a dinâmica já estabelecida entre as crianças e os adultos. Para Bauman (2001, p. 111):

Os estranhos se encontram numa maneira adequada a estranhos. Um encontro de estranhos é diferente de encontros de parentes amigos, ou conhecido. No encontro de estranhos náo há uma retomada a partir do ponto em que o último encontro acabou, nem troca de informaçóes sobre as tentativas, atribuiçóes ou alegrias desse intervalo, nem lembranças compartilhadas: nada em que se apoiar ou que sirva de guia para o presente encontro. $\mathrm{O}$ encontro de estranhos é um evento sem futuro (o esperado é que não tenha futuro), uma história para "não ser continuada", uma oportunidade única a ser consumada enquanto dure esse ato.

Diante desse desafio, o pesquisador precisa assumir uma postura de humildade, desenvolver uma atitude de escuta sensível (BARBIER, 2007). É preciso esperar o tempo de abertura do outro, permeado por momentos de recuo e momentos de uma observação mais participativa e comunicativa.

Esse processo implica reconfigurar nossa postura de pesquisador para conquistar os sujeitos envolvidos, uma vez que a etnografia pressupóe um longo tempo de estadia no campo de investigação. Na pesquisa mencionada neste texto, o tempo de presença foi de nove meses. A permanência no campo possibilitou-nos desenvolver o olhar em $3 D$, um exercício que buscou ampliar a visão, a capacidade de observar as dinâmicas em perspectiva; ver não apenas com os olhos, mas estabelecer relaçáo corporal, de proximidade, de toque, manifestada em açóes de cooperação, de suporte às solicitaçóes tanto das crianças, como dos adultos. $\mathrm{Ou}$ seja, observar por diferentes ângulos, capturar as cenas por instrumentos distintos - pela lente da câmera, na emoção da narrativa no diário de campo.

Outro elemento fundamental na etapa de inserção no campo de pesquisa foi a atitude de escuta, respeitando o tempo de abertura do outro. Atitude que nos permitiu refletir e retomar os objetivos propostos, o que de fato queríamos observar e compreender. Qual era o nosso foco de pesquisa? O olhar em 3D para as manifestaçóes das crianças e dos adultos e a atitude reflexiva nos confrontavam com os conceitos e

8 Bauman (2001, p. 111) diz que "uma cidade é um assentamento humano em que os estranhos têm chance de se encontrar." Isso significa, para Bauman, que estranhos têm chance de se encontrar em sua condição de estranhos, saindo como estranhos do encontro casual que termina de forma tão abrupta quanto começou. 
princípios que constituíam a nossa compreensão acerca da experiência de pesquisa e de como poderíamos capturar as cenas e gerar os dados. A descrição no diário de campo foi utilizada sempre depois de sairmos da escola, constituindo-se como um tempo narrativo e reflexivo de todas as cenas observadas. A tessitura de comentários e questionamentos foi orientadora das observaçóes na etapa seguinte. $\mathrm{O}$ diário de campo foi um instrumento importante de rememoração do vivido em cada dia de observação.

Para Merleau-Ponty (1994), compreender os conceitos não diz respeito a uma filosofia idealista mas existencial, pois implica em refletir o que eles significam para nós, em nossas vidas e no mundo. Assim, captar fenomenologicamente a essência da percepção ${ }^{9}$ é compreender como a percepção efetivamente funciona em nossas relaçóes com o mundo circundante e com as outras pessoas. Nesse sentido, a essência não pode ser separada da existência, bem como a compreensão conceitual separada da compreensão do mundo ao qual se refere.

Essa proximidade, por meio de uma relação cada vez mais próxima, com cumplicidade e sintonia, ampliou as possibilidades de captura das complexidades das dinâmicas, nas interaçóes entre criança-criança, professor-criança, no sentido de perceber os processos vividos pela criança nos momentos observados, nas suas curiosidades e investigaçóes, nas suas iniciativas de participação, nas brincadeiras, no banho, nas trocas, nas refeiçóes, no sono, no choro e nas risadas. Cada vez mais havia o convite para a pesquisadora se envolver nas atividades. Para Geertz (2008, p. 20), "A prática da etnografia é estabelecer relações, selecionar informantes, transcrever textos, levantar genealogias, mapear campos, manter um diário de campo."

Essa etapa da pesquisa nos permitiu compreender o quanto a inserção no campo de pesquisa é marcada pelo exercício de aproximação, pelo estabelecimento de vínculos e afetos, por ajustes de procedimentos do pesquisador para com o grupo e do grupo para com o pesquisador. Uma vez que o pesquisador não é neutro, ele é parte das relaçóes, suas açóes interferem nas dinâmicas dos sujeitos observados. Exige, portanto, do pesquisador a disposição para perceber pela escuta sensível o quanto a sua presença afeta e altera as dinâmicas e igualmente se permitir ser afetado, ou seja, acolher o afeto dos sujeitos pesquisados.

9 Chauí, a partir de Merleau-Ponty, conceitua a percepção como um modo de nossa consciência relacionarse com o mundo exterior pela mediação do nosso corpo. "A percepção é uma vivência dotada de estrutura: há o ato de perceber (pela consciência) e há o correlato percebido (a coisa externa); a característica principal do percebido é a de oferecer-se por faces, por perfis ou perspectivas, como algo interminável que nossos sentidos nunca podem apanhar de uma só vez e de modo total [...] é uma vivência da consciência, um ato cujo correlato são qualidades percebidas pela mediação do nosso corpo; é um modo de estarmos no mundo e de nos relacionarmos com a presença das coisas diante de nós, é um modo diferente, por exemplo, da vivência imaginativa, da vivência reflexiva." (CHAUÍ, 1995, p. 236). 
Para Passos e Barros (2009), toda pesquisa se constitui num processo de intervençâo e exige do pesquisador um mergulho no plano da experiência, em que o conhecer e o fazer se tornam inseparáveis, impedindo qualquer pretensão à neutralidade. "Conhecer é, portanto, fazer, criar uma realidade de si e do mundo, o que tem consequências políticas. [...] o método, assim, reverte seu sentido, dando primado ao caminho que vai sendo traçado sem determinaçóes ou prescriçoóes de antemão dadas.” (p. 30).

Capturar as interaçóes e se deixar ser capturado pelas dinâmicas são atitudes que precisam se efetivar no processo da pesquisa, como nos indica Geertz (2008, p. 20): "a etnografia é uma descrição densa." O que o etnógrafo enfrenta de fato são as rotinas, uma multiplicidade de estruturas conceptuais complexas, muitas delas sobrepostas ou amarradas umas às outras, que são simultaneamente estranhas, irregulares e inexplicáveis. Primeiramente, o etnógrafo precisa apreendê-las e depois apresentá-las de forma descritiva e consistente. Trata-se de exercício a ser desenvolvido em todos os momentos no seu trabalho de campo, tanto nas açóes rotineiras como nas mais inusitadas, uma vez que:

A etnografia é uma descrição densa. O que o etnógrafo enfrenta de fato é uma multiplicidade de estruturas conceptuais complexas, muitas delas sobrepostas ou amarradas uma as outras, que são simultaneamente estranhas, irregulares e inexplícitas, e que ele tem que, de alguma forma, primeiro apreender e depois apresentar. (GEERTZ, 2008, p. 20).

O instrumento do olhar em $3 D$ permitiu que a mesma cena fosse capturada e interpretada a partir de várias dimensóes; ora a lente ou o olhar focavam numa criança em particular para tentar perceber os movimentos, o corpo em ação e suas narrativas; ora o efeito zoom se voltava para as interaçóes mais coletivas, num movimento do particular para o coletivo e vice-versa. Essa mesma cena capturada pela lente da câmera era posteriormente narrada no diário de campo.

No movimento de captura, o registro em vídeo e as fotografias foram recursos técnicos que permitiram descrever os detalhes e as nuances interativas entre as crianças e delas com a professora, com o intuito de congelar manifestaçóes, para depois narrá-las e descrever como o corpo se torna um recurso na produção e manifestação da linguagem. A terceira dimensão sempre presente é a dimensão da emoção e dos afetos. O que, nessa cena, capturou nossa atenção para que nela focássemos nossa observação?

É importante ressaltar que essa percepção afetiva também estará muito presente no momento de descrever as experiências vividas no campo da pesquisa. 
Essas vivências no processo de adaptação reconfiguraram os objetivos da pesquisa. Para pesquisar com, precisamos estar abertos ao que o outro nos mostra; nesse sentido, os objetivos nunca estáo totalmente definidos, eles se definem na própria dinâmica da pesquisa.

É importante ressaltar que essa percepção afetiva também estará muito presente no momento da compreensão e interpretação das situaçóes observadas, perceber e acolher os saberes do corpo das crianças, os sentidos e primeiras impressóes, uma vez que ela experimenta, vive no corpo suas primeiras impressóes, ela apreende o mundo com seu corpo. Essas vivências no processo de adaptação reconfiguraram os objetivos da pesquisa. Para pesquisar com, precisamos estar abertos ao que o outro nos mostra; nesse sentido, os objetivos nunca estáo totalmente definidos, eles se definem na própria dinâmica da pesquisa ${ }^{10}$.

\subsection{A atitude de escuta e a reorganização dos objetivos da pesquisa}

Como já explicitado, a atitude de escuta foi uma ferramenta importante no processo de aproximação e apreensão do objeto de pesquisa. A escuta sensível se constituiu numa atitude de respeito ao tempo do outro, de espera, de não invasáo do espaço da criança e dos adultos - fundamental na fase da imersão, no processo de constituição de relações de afeto com os sujeitos da pesquisa. Para Barbier, a escuta é uma postura diante dos desafios do campo empírico.

Trata-se de um escutar-ver [...] a escuta sensível apoia-se na empatia. $O$ pesquisador deve saber sentir o universo afetivo, imaginário e cognitivo do outro para "compreender do interior" as atitudes e os comportamentos, o sistema de ideias, de valores, de símbolos e de mitos. [...] A escuta sensível reconhece a aceitação incondicional do outro. Ela não julga, não mede, não compara. Ela compreende sem, entretanto, aderir às opinióes ou se identificar com o outro, com o que é enunciado ou praticado. A escuta sensível afirma a coerência do pesquisador. Este comunica suas emoçôes, seu imaginário, suas perguntas, seus sentimentos

10 Geertz afirma que após o questionamento à visão colonialista, em meados do século XX, a antropologia teve que revisar seus métodos e teorias. Houve uma alteraçáo importante na relaçáo do pesquisador com os seus pesquisados. Segundo o autor, a natureza das relaçôes "entre os que perguntam e olham e os que são perguntados e se tornam objetos do olhar" tornou-se outra (1989, p.58). Talvez nosso olhar colonizador para as crianças necessite também ser revisado. 
profundos. Ele está "presente", quer dizer, consistente. (BARBIER, 2007, p. 94).

A atitude de escuta provocou sensíveis alteraçóes nos objetivos iniciais da pesquisa. À medida que o pesquisador decide ouvir e perceber os sujeitos do campo e eles apresentam outros aspectos a serem observados, abrem-se novas perspectivas, provocam o pensar em outros aspectos presentes nas dinâmicas. Dessa maneira, a pesquisa com as crianças começa a se processar de modo diferente do imaginado, uma vez que os objetivos que tínhamos previamente definidos foram ressignificados ao longo do período de permanência no campo pelas açóes de pesquisa.

Assim, pesquisar com implica perceber e acolher as diversas manifestaçóes dos corpos em movimento das crianças. Essa observação atenta nos permitiu delinear as dinâmicas das crianças nos ambientes e também deslocou nosso olhar para as açóes dos docentes.

As posturas dos professores foram questionadas em alguns momentos. Observamos sua falta de compreensão sobre os processos do desenvolvimento infantil, bem como a manifestação de um modelo de organização didáticopedagógica excessivamente centrada nos adultos, característica marcante da cultura escolar tradicional na qual há um controle sobre as iniciativas das crianças e sua participação efetiva no planejamento e execução das atividades. Mesmo identificando esses elementos no desenvolvimento das açóes cotidianas, foi igualmente possível, nas ações de educação e cuidado, capturar doçura e delicadeza nos gestos, no afago, no atendimento das solicitaçóes das crianças.

\subsection{A observação das rotinas e a captura do inesperado}

A rotina, como categoria pedagógica que organiza as dinâmicas na Educação Infantil, foi amplamente estudada por Batista (1998), Barbosa (2006), Rodrigues (2009) e Martins Filho (2012). Esses estudos buscaram compreender as nuances daquilo que está presente todos os dias - por exemplo, chegada, saída, sono, banho, trocas, refeiçóes, em oposição ao rotineiro, ou que está preso a grades de horários, com atividades sequenciadas previamente definidas - recepção das crianças das $7 \mathrm{~h}$ às $7 \mathrm{~h} 30$, lanche das $7 \mathrm{~h} 30$ às $8 \mathrm{~h} 00$ e assim sucessivamente; um é $\mathrm{o}$ quotidiano e o outro é a rotina.

No entanto, a rotina pode ser entendida de modo mais dinâmico, envolvendo também o inesperado, o que não acontece sempre da mesma maneira. Barbosa (2006) identifica nas rotinas pedagógicas quatro elementos constitutivos: a) a organização do ambiente; b) o uso do tempo; (c) a seleção e as propostas de atividades; (d) a seleção 
e a oferta de materiais. Segundo a autora, esses elementos definem modos de pensar, prescrever e padronizar as rotinas. Para Barbosa (2006, p. 201):

A rotina é compreendida como uma categoria pedagógica da educação infantil que opera como a estrutura básica organizadora da vida coletiva diária [...]. Fazem parte das rotinas todas as atividades que são recorrentes ou reiterativas na vida coletiva, mas que, nem por isso, precisam ser repetitivas, isto é, feitas da mesma forma todos os dias.

$\mathrm{Na}$ escola pesquisada, apesar de não haver uma grade de atividades preestabelecidas, havia uma sequência na qual as dinâmicas se repetiam. Alguns exemplos são a acolhida das crianças, com um horário definido de chegada, as refeições sempre no mesmo horário, o banho após brincar no parque de areia, o sono coletivo após o almoço.

Nessas atividades, consideradas como rotina, havia um controle maior do professor. Nas brincadeiras livres no parque ou internamente na sala, ou entre essas rotinas, como esperar que o almoço ficasse pronto, havia mais liberdade para as inovaçóes das crianças. Nesses momentos, capturamos cenas inusitadas. Esses momentos foram ricos de observação das crianças, nos quais o espírito investigativo e criativo mais se evidenciava, e as ações do mover-se em liberdade (PIKLER, 2010) se constituíam em possibilidades de aprendizagens, criação e combinaçóes de brincadeiras. É o que podemos observar nesta cena:

Os brinquedos estavam disponíveis no fundo da sala em três caixas de papeláo. A professora estava ocupada organizando um material para apresentação na reunião dos pais. Orientados diretamente pela professora, as crianças elaboravam uma pintura de um painel; nesse momento, a professora intervinha diretamente nas ações das crianças, orientando como deveriam proceder. As nossas observaçóes se dividiam entre o que acontecia com a elaboraçáo do painel e as brincadeiras das demais crianças espalhadas pela sala. Deparo-me com uma cena interessante. Dois meninos brincavam de cortar o cabelo. O primeiro senta na cadeira, coloca a cabeça para trás. O outro pega um pedaço de TNT (tecido náo tecido) e coloca sobre ele, como se estivesse no cabelereiro. Amarra o tecido e depois reproduz movimentos que evidenciam a intencionalidade de quem está lavando o cabelo, depois cortando, finaliza o trabalho com um secador. Logo em seguida, fazem o movimento de inversão 
das tarefas. Nesse momento, eles percebem que estão sendo filmados, se afastam um do outro, procurando outros grupos de crianças. (Diário de campo, setembro de 2012).

Nesses momentos, podemos constatar que a criança, num ambiente rico em possibilidades, não precisa que o adulto, a todo o momento, dirija e controle seus processos de aprendizagem. As crianças demonstraram muitas iniciativas de explorar os ambientes e objetos, bem como as materialidades no seu entorno.

\subsection{A saída do campo: a escrita como uma experiência de teorizar o vivido}

O outro aspecto da pesquisa importante a ser discutido é o processo de distanciamento após a vivência no campo de pesquisa. Nessa etapa, há uma imbricação profunda entre método e teoria. A experiência de escrita se constitui, portanto, num processo de açáo reflexiva sobre o vivido, com intuito de descrever e interpretar as dinâmicas observadas, compilar situaçóes e ampliar a compreensáo do vivido no campo de pesquisa. Assim, nasce também o desejo de compartilhar as nossas experiências de aprendizagem vividas com as crianças.

Nessa perspectiva, a ação de escrita nos coloca diante do desafio do pensamento inovador de abertura e exercício de pensar e elaborar conceitos e ideias nunca pensadas.

Necessitamos nos reeducar para fazer do escrever um ato inaugural; não apenas transcrição do que tínhamos em mente, do que já foi pensado ou dito, mas inauguraçáo do próprio pensar. (MARQUES, 1997, p. 13).

De acordo com Larrosa (2002), experiência é algo singular, que nos passa; não apenas acontece, nos toca. $\mathrm{O}$ que nos passa se constitui tanto como uma iniciação nos mistérios do objeto em análise, como um elemento de transformação de significação do pensar. Ainda em conformidade com o autor:

A experiência não é o que acontece, mas o que nos acontece, duas pessoas, ainda que enfrentem o mesmo acontecimento, não fazem a mesma experiência. $\mathrm{O}$ acontecimento é comum, mas a experiência é para cada qual sua, singular e de alguma maneira impossível de ser repetida. $\mathrm{O}$ saber da experiência é um saber que não pode separar-se do indivíduo concreto em quem encarna. (LARROSA, 2002, p. 27). 
A escrita é, para quem escreve, algo singular, atravessa e modifica o sujeito. Para Merleau-Ponty, a experiência pode ser entendida como uma forma de comunicarse com mundo: "[...] ser uma consciência, ou, antes ser uma experiência, é comunicar interiormente com o mundo [...] uma primeira abertura às coisas sem a qual não haveria pensamento objetivo." (MERLEAU-PONTY,1996, p. 142).

O conceito de experiência em Merleau-Ponty é analisado por Chauí (2002). Para a autora, o conceito de experiência desenvolvido pelo filósofo pode ser entendido como um processo de iniciação aos mistérios do mundo.

A experiência já não pode ser o que era para o empirismo, isto é, passividade receptiva e resposta a estímulos sensoriais externos, mosaico de sensaçôes que se associam mecanicamente para formar percepçóes, imagens e ideias; nem o que era para o intelectualismo, isto é, atividade de inspeçáo intelectual do mundo. Percebida, doravante como nosso modo de ser e existir no mundo, a experiência será aquilo que sempre foi: uma iniciação aos mistérios do mundo. É à experiência que nos dirigimos para nos abra ao que não é nós. (CHAUÍ, 2002, p. 161).

A partir desse argumento, podemos defender que o ato de escrever e descrever as situaçóes vividas passa a ser um tipo de experiência que nos abre aos mistérios do mundo, um rico exercício de pensamento; não uma mera transcrição do vivido, mas algo pensado e refletido. Nesse sentido, na ação de escrever, o pensamento inovador é construído, toma forma e constitui-se numa análise sobre o percebido. Na mesma esteira de raciocínio, Chauí sinaliza que o autor não convida o leitor para:

Reencontrar o que já sabia, mas toca nas significaçôes existentes para torná-las destoantes, estranhas, e para conquistar, por virtude desta estranheza, uma nova harmonia que se aposse do leitor, fazendo-o crer que existira desde sempre e que sempre pertencera. Escrever é essa astúcia que priva a linguagem instituída de centro e de equilíbrio, reordena ou reorganiza os signos e o sentido e ensina tanto ao escritor como ao leitor o que sem ela não poderiam dizer em pensar, pois a palavra náo sucede nem antecede o pensamento porque é sua contemporânea. (CHAUÍ, 2002, p. 19).

Quem escreve é desafiado a escrever como quem busca desvendar os sentidos do mundo - uma experiência original. Chauí, apoiada em Merleau-Ponty, afirma 
que o que torna possível a experiência é a existência de uma falta ou de uma lacuna a serem preenchidas:

[...] sentidas pelo sujeito como intenção de significar alguma coisa muito precisa e determinada, que faz do trabalho para realizar a intenção terminada, que faz do trabalho para realizar a intenção significativa o próprio caminho para preencher seu vazio e determinar sua indeterminação, levando à expressão o que ainda e nunca havia sido expresso. Há uma intenção de significar que é, simultaneamente, um vazio a ser preenchido e um vazio determinado que solicita o querer-poder do agente, suscitando sua ação significadora a partir do que se encontra disponível na cultura como falta e excesso que exigem o surgimento de um sentido novo. (CHAUÍ, 2002, p. 153).

O ato de escrita e da tessitura da análise dos dados é criativo e nos impulsiona ao que não somos. Trata-se de um desafio que nos lança ao novo, ao diferente, aos mistérios dos pensamentos ainda não pensados, uma aventura, um exercício de pensar que nos proporciona novas aprendizagens, novas perspectivas sobre fenômeno estudado. As leituras anteriores ao momento de ingresso no campo já não bastam, somos chamados pelas novas palavras que nos penetram pelo olhar, pelas vozes e pelas perguntas que as situaçôes vividas trazem à nossa mente.

Dessa forma, a escrita pode ser entendida como um ato de compreensão, uma busca, uma aproximaçáo aos desafios do tema preferencialmente tratado numa obra ou num texto. Essa ação exige do escritor uma capacidade ampliada, que vai além das leituras e do domínio dos conceitos básicos. Exige também do escritor a utilização apropriada dos recursos da linguagem, para que essa experiência possa ser partilhada de forma compreensivelmente comunicável. Logo, tanto o estar com as crianças como o escrever e teorizar o vivido são um ato inaugural: só escrevendo se escreve. É pela experiência de escrita, no processo de análise, que ressignificamos o vivido.

Importa o fato de que, ao que, ao escrever, estou sob a mirada de muitas leituras. Acho-me numa interlocuçáo de muitas vozes que me agitam, conduzem, animam, perturbam. É isso que faz de me escrever uma interlocução de muitas vozes, uma amplificação de perspectivas, abertura de novos horizontes, construção de saberes. (MARQUES, 1997, p. 26). 
Essa é uma dimensão da experiência de escrita que não se reduz ao ato mecânico, mas uma ação que exige do escritor a entrega ao processo. Trata-se de uma experiência que se constrói no fazer e que provoca tanto no escritor como no leitor outros entendimentos acerca do tema desenvolvido; é um fazer que nos retira do lugar onde estamos, propiciando outras perspectivas para compreender e pensar os problemas do nosso tempo.

\subsection{A experiência de partilha: o que as crianças nos ensinaram}

Por meio da escrita, podemos compartilhar os nossos achados com as crianças. Elas nos ensinaram que as novas aprendizagens são uma grande aventura de descoberta; elas aprendem e compreendem fazendo, experimentando uma, duas, três vezes até conseguir. Elas vão do ato ao pensamento, como explicitou Wallon (2008), da ação para a elaboração conceitual.

A observação muitas vezes indicou que os adultos desconsideravam esses processos nas crianças e esperavam que ouvissem passivamente as instruçóes, para depois executar, seguindo as orientaçóes determinadas, muitas vezes, sem a possibilidade de efetuar inovaçóes.

$\mathrm{Na}$ cena narrada a seguir, a professora planejava construir um painel para expor na feira de visitação para os pais. Primeiramente, a professora recortou uma folha de papel de cerca de 1,5 por 3,0 metros e fixou-a na parede. Ela então solicitou que todas as crianças se sentassem, pois iria explicar como seria feito o painel.

Depois das crianças serem dispostas sentadas num círculo, a professora explica que irão construir um painel juntas. Que cada criança poderá ajudar a fazer o painel que será exposto à visitação dos pais, por isso, as crianças deveriam caprichar bastante. Ela coloca tinta em pratos de plástico, cores diferentes em cada prato, azul, marrom, amarelo, vermelho, branco. As crianças deveriam ficar sentadas, observando e esperando a sua vez de pintar o painel. As duas ajudantes da professora, neste dia, exerciam funçóes diferentes: enquanto uma passava a tinta na mão da criança com o pincel, a outra estava sentada com as crianças, observando-as e acalmando-as, para que elas pacientemente esperassem chegar a sua vez. No momento em que a criança iria dar a sua contribuição à feitura o painel, ela poderia escolher a cor que sua máo seria pintada e onde queria que fosse deixada a sua marca. A professora segurava a máo da 
criança cheia de tinta, fazia marcas das mãos no formato de árvores, flores, conforme ela indicava. Essa ação sucessiva foi gradativamente ganhando o formato a uma paisagem. (Diário de campo, outubro de 2012).

Essa cena evidencia um tipo de participação que limita a criatividade e a ação inovadora da criança, uma vez que o ato de criação estava centrado na professora, que de fato tinha o controle dos processos. A todo o momento, as crianças buscavam um papel mais ativo e enviavam sinais sobre o quanto elas queriam participar ativamente da feitura do painel, com seus corpos em ação, manipulando as tintas, experimentando as cores e traços. Para as crianças, não existe limite na aventura de experimentar sensaçóes novas. Nesse sentido, os adultos devem oferecer ambientes e oportunizar vivências, mas são as crianças que vivem a experiência.

As crianças nos ensinaram que é necessária uma acolhida às suas iniciativas, com ambientes seguros e possibilidades de vivenciar situaçóes diferentes. As crianças precisam de ambientes seguros para que possam experimentar atividades diferentes; num planejamento diversificado e criativo, elas querem participar ativamente de todo o processo. A criança sabe o que pode com seu corpo e suas iniciativas são indicativos de sua potência pelo conhecer.

A experiência com as crianças nos ensinou que a valorização da participação delas não significa diminuição da autoridade e do poder do adulto. As crianças têm facilidade em compartilhar, e desde muito pequenas aprendem que é melhor brincar em conjunto do que sozinhas. O que os adultos precisam compreender é que a ação pedagógica deve ser uma ação de partilha de saberes e de decisóes, de como e quando realizar as tarefas. As crianças dizem com suas açóes: "queremos participar".

Os relatos de pesquisa nos confrontaram com a nossa própria condição de adultos, de como percebemos as crianças e sua capacidade de compreender o mundo. Elas nos ensinaram com ousadia sobre o desafio cotidiano de superação, de querer sempre experimentar o mundo, as novas possibilidades de seus corpos e relaçóes, repetir quantas vezes forem necessárias para incorporar, para superar, para modificar as aprendizagens. As crianças nos dizem com seus corpos em movimento que é muito bom experimentar as situaçóes novas e retomar as antigas.

Esse tipo de escrita pode ser caracterizado como uma escrita-experiência, ou algo que nos passa. Seria possível viver essa experiência e continuar sendo a mesma pessoa? A questão a ser pensada é a possibilidade de sermos transformados pela experiência de pesquisa, bem como a necessidade e a disposição de quem, ao viver a experiência de pesquisa, se permita ser transformado por ela. Esse é um 
tipo de experiência que nos deixa marcas, que provoca em nós uma mudança de perspectiva.

Partindo do pressuposto de que a experiência da escrita nos transforma, podemos igualmente dizer que o ato de escrever apresenta também uma dimensão de partilha do pensamento, um processo de abertura e de iniciação que não se vive só, como a produção deste texto. Ele se constituiu como uma produção inédita, que traz a narrativa de uma vivência que exigiu um rico exercício de pensamento e leituras, com o confronto de argumentos.

O momento de escrita e de teorização do vivido é um convite aos leitores a uma reflexão em torno da temática. Portanto, trata-se de uma escrita-experiência, ou seja, uma escrita que teoriza o vivido. Não se constitui num texto fechado, concluído, acabado, mas sim num texto aberto, um convite para pensar em conjunto. Dessa forma, o texto sempre sinaliza os caminhos percorridos, fala das nossas escolhas e das nossas leituras e filiações teóricas. Além disso, ele apresenta os questionamentos produzidos, mas numa perspectiva de abertura aos mistérios da temática de estudo proposta.

Nesta outra cena observada numa turma de crianças de 2 a 3 anos, a professora estava desenvolvendo com as crianças o conhecimento de si e a nomeação das partes do corpo.

A professora recortou pedaços de papel pardo do tamanho das crianças, e com o pincel atômico contornou cada criança. Depois de contornado o formato do corpo da criança, as crianças deveriam desenhar, as partes do seu corpo. Depois de concluída a tarefa, a professora escreveu o nome de cada criança na folha de papel e fixou na parede. No final do dia, quando as mães vieram buscar as crianças, um menino chama a máe, a segura pelo braço e a leva diante do seu desenho e diz: "olha mãe eu aqui". (Diário de campo, setembro de 2012).

Nessa cena, é possível perceber uma participação mais efetiva da criança, com liberdade de criação e ação autônoma para produzir as suas impressôes dela mesma. Essa experiência foi tão significativa que a criança quis compartilhá-la com a mãe e expressar os conhecimentos apreendidos na escola.

O desejo de compartilhar as aprendizagens é inerente ao ser humano. Nessa cena, a criança compartilhou com a mãe, e nós, pela escrita, podemos compartilhar as novas aprendizagens, bem como instigar e provocar os leitores a outras formas de pensar, a outros entendimentos. Portanto, esses momentos de escrita se constituem em profundos espaços de liberdade de pensamento e 
transformação de quem escreve, que, ao escrever, rememora toda a experiência vivida, significando-a em outro patamar. Nesse sentido, recorremos mais uma vez a Marques, que fala da imprescindível ação de escrever.

Escrever é preciso, para encontrar-se a si mesmo sendo mais forte do que se é, para a longa e tortuosa busca do outro de um desejo mais paciente. Importa em duplo desconhecimento: o do que somos e podemos e o de outrem que misterioso os aguarda. Trabalhando pela dúvida inaugural da criação, o escrevente busca achar-se, descobrir-se para além das circunstâncias imediatas. (MARQUES, 1997, p. 43).

Diríamos que pesquisar é preciso, pois sem a pesquisa não teríamos o que escrever. É fundamental pesquisar com as crianças, para aprender com elas e sobre elas.

\section{Considerações finais}

Este texto propôs uma reflexão sobre dois momentos significativos que integram a ação de pesquisar com as crianças. $O$ primeiro deles é o rico momento de estar com as crianças e ser desafiado a apreender os sentidos de suas açóes. $\mathrm{O}$ segundo momento envolve a ação de teorizar o vivido, de explicitar e evidenciar o que foi aprendido - um momento de partilha e de contribuição ao debate.

Este texto propôs uma reflexáo sobre dois momentos significativos que integram a ação de pesquisar com as crianças. O primeiro deles é o rico momento de estar com as crianças e ser desafiado a apreender os sentidos de suas açóes. $\mathrm{O}$ segundo momento envolve a ação de teorizar o vivido, de explicitar e evidenciar o que foi aprendido - um momento de partilha e de contribuiçáo ao debate por meio da escrita.

Pesquisar é compreender um dado objeto de estudo, ir ao encontro do que não se sabe. Assim, num dado momento da pesquisa, foi necessário nos desapegarmos de nossas hipóteses e nos colocarmos numa atitude de abertura e diálogo, como um mergulho de corpo inteiro no campo. Estar com as crianças implica em estar aberta ao que elas queriam nos dizer com seus corpos, movimentos, olhares. Uma atitude de escuta. Pesquisar com as crianças sugere a construção de instrumentos metodológicos que nos ajudem a visibilizar as suas percepçóes sobre o mundo.

$\mathrm{Na}$ experiência de escrita, é preciso nos deixar envolver tanto pelo processo de rememorar a experiência vivida no campo empírico como no processo de análise e interpretação do vivido. Evidencia-se que a produção da escrita envolve certa ruptura com a barreira da tela em branco e o início de uma escrita que 
contenha a apropriação de outras compreensôes, a ampliação de conceitos já assimilados, bem como a incorporação de outros nós que emerjam das relaçóes que se estabeleceram nos processos investigativos. Esse é um momento em que compartilhamos com nossos leitores a experiência intensa da pesquisa e nossos encontros com as crianças e com nossos interlocutores teóricos.

Essa experiência não poderia deixar de nos modificar, atravessar e impactar nossas formas de pensar o mundo. A experiência é algo singular, que nos passa e nos atravessa, uma ação de singularidade; é um ato inaugural, que nos impulsiona a novas experiências de escrita, novos textos, outros encontros.

As crianças nos ensinaram que o movimento de aprender é sempre um processo de iniciação aos mistérios do mundo. Em nossa experiência de pesquisar com as crianças, o grande desafio foi o de decifrar seus movimentos, suas açóes, descobertas e aprendizagens, o que poderíamos denominar de dimensão corpórea das aprendizagens das crianças. Os dois momentos aqui descritos se complementam na ação de pesquisar com crianças, estar com elas, escrever, teorizar o vivido, compartilhar sobre o que elas nos ensinaram. É uma aprendizagem que nunca termina, mas nos instiga a novas aventuras de pesquisa.

\section{Referências}

BARBIER, Rene. A pesquisa açáo. Brasília: Líber livro, 2007.

BARBOSA, Carmen Silveira. Por amor e por força, rotinas na educaçáo infantil. Porto Alegre: Artmed, 2006.

BATISTA, Rosa. A Rotina no dia-a-dia da creche: entre o proposto e o vivido. Dissertação (Mestrado em Educação) - Universidade Federal de Santa Catarina, Florianópolis, 1998.

BAUMAN, Zygmunt. Modernidade liquida. Rio de Janeiro: Zahar, 2001.

BEBER. Irene Carrillo Romero. As experiências do corpo em movimento das crianças pequenas: reflexōes para a pedagogia da Infância. Tese (Doutorado) Programa de Pós-Graduação em Educação- UFRGS, 2014.

COHN, Clarice. Antropologia da criança. Rio de Janeiro: Zahar, 2005.

CARDOSO, Roberto O Trabalho do Antropólogo: olhar, ouvir, escrever. Disponível em: <www.revistas.usp.br/ra/article/viewFile/111579/109656>

CHAUÍ, Marilena. Experiência do pensamento. São Paulo: Martins Fontes, 2002. 
DESCARTES, René. O discurso sobre o método. São Paulo: Martins Fontes, 2003. GEERTZ, Clifford. A interpretaçáo das culturas. Rio de Janeiro: LTC, 2008. GEERTZ, Clifford. Estar lá, escrever aqui. Disponível em: <http://www2.fct. unesp.br/docentes/geo/necio_turra/PPGG\%20\%20PESQUISA\%20QUALI\%20 PARA\%20GEOGRAFIA/Estar\%201\%E1,\%20escrever\%20aqui.pdfs

LÉVI-STRAUSS, Claude. Olhar escutar ler. São Paulo: Companhia das Letras, 1977.

LOPES DA SILVA, Aracy; NUNES, Angela; MACEDO, Ana Vera Lopes da Silva (Org.) Crianças indígenas: ensaios antropológicos. São Paulo: Global, 2002.

MARQUES, Mário Osório. Escrever é preciso: o princípio da pesquisa. Ijuí: Editora Unijuí, 1997.

MERLEAU-PONTY. Fenomenologia da percepção. Martins Fontes, 1996. . Conversas-1948. São Paulo: Martins Fontes, 2004. . Psicologia e pedagogia da criança. São Paulo: Martins Fontes, 2006.

LARROSA, Jorge. Notas sobre a experiência e o saber de experiência. Revista Brasileira de Educação, p. 20-28, jan./fev./mar./abr. 2002.

PASSOS, Eduardo; KRASTRUP, Virgínia; ESCÓSSIA, Liliana (Org.). Pistas do método da cartografia: pesquisa-intervenção e produção da subjetividade. Porto Alegre: Sulina, 2009.

PIKLER, Emmi. Mover se en Libertad: desarrollo de la motricidad global. Madrid: Narcea S. A. Ediciones, 2010.

WALLON, Henri. Do ato ao pensamento. Petrópolis: Vozes, 2008.

WWW.TECMUNDO.com.br/video/2469-como-funciona-a-tecnologia-3d-.htm. 